\title{
Effect of L-Deprenyl on the Putrescine Level and Neuronal Damage after Transient Global Cerebral Ischemia in Gerbils
}

\author{
Hyung Lee1, Yeun-Kyung Chu², Joon-Ho Shon ${ }^{2}$, Kyung-Hee Chun³, Jee-In Kim4, Seong-Ryong Lee ${ }^{5 *}$ \\ ${ }^{1}$ Department of Neurology, School of Medicine and Brain Research Institute, Keimyung University, Daegu, Korea \\ ${ }^{2}$ School of Kinesiology, Yeungnam University, Gyeongsan, Korea \\ ${ }^{3}$ Department of Medical Education, School of Medicine, Yeungnam University, Daegu, Korea \\ ${ }^{4}$ Department of Molecular Medicine, Obesity-Mediated Disease Research Center, School of Medicine, Keimyung University, \\ Daegu, Korea \\ ${ }^{5}$ Department of Pharmacology, Obesity-Mediated Disease Research Center, School of Medicine, Keimyung University, Daegu, \\ Korea \\ Email: *srlee@dsmc.or.kr
}

How to cite this paper: Lee, H., Chu, Y.-K., Shon, J.-H., Chun, K.-H., Kim, J.-I. and Lee, S.-R. (2017) Effect of L-Deprenyl on the Putrescine Level and Neuronal Damage after Transient Global Cerebral Ischemia in Gerbils. International Journal of Organic Chemistry, 7, 171-184.

https://doi.org/10.4236/ijoc.2017.72014

Received: April 18, 2017

Accepted: June 19, 2017

Published: June 22, 2017

Copyright () 2017 by authors and Scientific Research Publishing Inc. This work is licensed under the Creative Commons Attribution International License (CC BY 4.0).

http://creativecommons.org/licenses/by/4.0/

\begin{abstract}
L-Deprenyl is selective and irreversible monoamine oxidase B inhibitor, known to have neuroprotective properties. Putrescine, one of polyamine, is thought to be important in the neuronal cell damage associated with various type of excitatory neurotoxicity. We examined the effects of L-deprenyl on the changes in putrescine level and neuronal damage after transient global ischemia in gerbils. Male Mongolian gerbils weighing $65-75 \mathrm{~g}$ were used in the experiment. Global ischemia was induced by occlusion of common carotid arteries for $3 \mathrm{~min}$ to observe neuronal injury in hippocampal pyramidal cells. L-Deprenyl group was given $10 \mathrm{mg} / \mathrm{kg}$ of L-deprenyl intraperitoneally immediately after, $3 \mathrm{~h}$ and $6 \mathrm{~h}$ after global ischemia. Treated animals were processed in parallel with ischemic animals receiving saline as a vehicle and with shamoperated controls. Hippocampal putrescine level was increased by global ischemia and inhibited by L-deprenyl treatment. In histological findings, counts of viable neurons were made in the pyramidal cell layer of the hippocampal CA1 area 3 days after ischemic insult. The number of viable neurons in the pyramidal cell layer of CA1 area was significantly increased in animals treated with L-deprenyl compared to vehicle-treated ischemic animals $(\mathrm{p}<$ 0.05). In terminal deoxynucleotidyl transferase (TdT)-mediated dUTP nick end-labeling (TUNEL) assay, semiquantitative analysis of dark-brown neuronal cells was made in the hippocampal CA1 area. There was also a significant difference in the degree of TUNEL staining in the hippocampal CA1 area between vehicle-treated and L-deprenyl-treated animals $(\mathrm{p}<0.05)$. These data show L-deprenyl is effective as a prophylactic treatment for neuronal injury
\end{abstract}


when it is administrated before ischemia but a further study need to know the effects of administration of L-deprenyl after ischemia and at given times after reperfusion.

\section{Keywords}

L-Deprenyl, Polyamine, Global Ischemia, Hippocampus, Gerbil, Neuroprotection

\section{Introduction}

The naturally occurring polyamines in mammalian cells are putrescine (PU), spermidine (SD), and spermine (SM) that play an essential role in the process of cellular growth, development, and differentiation [1] [2]. Endogenous polyamines have multiple effects in the central nervous system and have been suggested to be neurotransmitters or neuromodulators [3]. Various kinds of stressful stimuli including stresses, seizures, excitotoxic conditions, and traumatic brain injuries increase the polyamines responses [4]-[10]. The changes in brain polyamine levels after brain ischemia have been studied [11] [12] [13] and polyamines, especially putrescine is thought to be important in the generation of brain edema, blood-brain barrier breakdown and neuronal cell damage associated with various type of brain injury including brain ischemia and trauma [4] [5] [6] [11] [12] [14]. Strategies including the inhibition of polyamine metabolism have been reported to have neuroprotective effect against ischemic neuronal injury [6] [11] [15].

L-Deprenyl (Selegiline) is a selective an irreversible inhibitor of monoamine oxidase-B (MAO-B) [16] [17] and a useful form of adjunct therapeutic drug to levodopa in the symptomatic treatment of Parkinson's disease [18]. And it has several other characteristics, which are independent of its action on MAO-B, include antioxidant action, induction of scavenger enzyme activity, and this may partially explain the described neuroprotection of L-deprenyl [19] [20] [21] [22]. L-Deprenyl is known to reduce the neurodegeneration in nigrostriatal dopamine system after chronic administration and recover the neurological symptoms of Alzheimer's disease [23] [24]. In addition, L-deprenyl showed anticonvulsive effect against various seizure models in mice [25]. However, the protective effect of L-deprenyl on the ischemic neuronal damage is controversial. This study was conducted to investigate whether L-deprenyl can attenuate the changes in PU level and neuronal damage following transient global ischemia in gerbils.

\section{Materials and Methods}

\subsection{Animals and Drug Administration}

Male Mongolian gerbils (Meriones ungiculatus) weighing 65 - $75 \mathrm{~g}$ (10-week old) were used in this study. These animals were housed in laboratory cages and maintained on a 12-h light-dark cycle, with ad libitum access to food and water 
throughout the study period. The gerbils were treated with L-deprenyl $(10 \mathrm{~m} / \mathrm{kg}$, i.p., purchased from RBI Laboratories, Natick, MA, USA). L-Deprenyl group was given $10 \mathrm{mg} / \mathrm{kg}$ of L-deprenyl intraperitoneally immediately after, $3 \mathrm{~h}$ and 6 $\mathrm{h}$ after global ischemia. L-Deprenyl was dissolved in normal saline. In the ischemic control groups, the vehicle (normal saline, i.p.) was administered to gerbils according to the same schedule of L-deprenyl.

\subsection{Surgery for Transient Global Ischemia}

Gerbils were sacrificed 3 days after global ischemia. Gerbils were anesthetized with isoflurane (3\% for induction and $1.5 \%$ for maintenance) with $\mathrm{N}_{2} \mathrm{O}(70 \%)$ and oxygen (30\%). In the supine position, a midline ventral incision of $2 \mathrm{~cm}$ was made in the neck. Both common carotid arteries were exposed, separated carefully from the vagus nerve and vein and occluded for $3 \mathrm{~min}$ with micro-clips [26]. Blood flow during the occlusion and reperfusion after removal of the clips was confirmed visually and the incision was closed. The rectal temperature was monitored and maintained at $37^{\circ} \mathrm{C} \pm 0.5^{\circ} \mathrm{C}$ with a feedback-controlled thermoregulator (CMA, Stockholm, Sweden) and an incandescent light was placed over the head from the induction of anesthesia until $3 \mathrm{~h}$ after ischemia. In the shamoperated group, the neck incision was made only to expose both common carotid arteries without occlusion. Other procedures were identical to those of other groups.

\subsection{Polyamine Extraction and High Performance Liquid Chromatography (HPLC) Analysis}

The animals were sacrificed $6,12,24$, or $72 \mathrm{~h}$ after ischemia for polyamine extraction. The brains were removed rapidly from the skull and dissected for separation of the hippocampus. The extraction procedure was carried out in icechilled conditions. Derivation and HPLC analysis of polyamines were based upon the previous method [9]. Each brain sample was homogenized with a glass tissue homogenizer in 10 volumes of ice-chilled $0.4 \mathrm{M}$ perchloric acid containing $2 \mathrm{mM}$ disodium EDTA and 1,8-diaminooctane $4 \times 10^{-5} \mathrm{M}$ as an internal standard. The homogenate was centrifuged at $12,000 \mathrm{~g}$ for $10 \mathrm{~min}$, at $4^{\circ} \mathrm{C}$ and $100 \mu \mathrm{l}$ of the supernatant was evaporated by a vacuum drier. The dried tissue was dissolved in $100 \mu \mathrm{l}$ of $1 \mathrm{M}$ sodium bicarbonate then deprived with $300 \mu \mathrm{l}$ of 4 -fluoro-3-nitrobenzo-trifluoride (FNBT) reagent (a mixture of $10 \mu \mathrm{l}$ of FNBT and one $\mathrm{ml}$ of dimethyl sulfoxide) at $60^{\circ} \mathrm{C}$ for $20 \mathrm{~min}$. At the end of derivation, $40 \mu \mathrm{l}$ of $1 \mathrm{M}$ histidine in $1 \mathrm{M}$ sodium bicarbonate was added to the reaction mixture then the derivation continued for another 5 min to scavenge excess FNBT. After cooling the mixture in an ice basket, the $\mathrm{N}-2$ '-nitro-4'-trifluoromethylphenyl derivatives of polyamines were extracted twice with $2 \mathrm{ml}$ of 2-methylbutane. After centrifugation (3000 $\mathrm{g}$ for $10 \mathrm{~min}$ ), the organic phase was evaporated and the residue was reconstituted with $1.0 \mathrm{ml}$ of methanol. The $20 \mu \mathrm{l}$ of the methanol solution was applied to the isocratic reversed phase HPLC system (Gilson Medical Electronics, France), then the separation of NTP-polyamines was accomplished 
by elution of acetonitrile-water (80:10, v:v) mobile phase at the flow rate of 1.0 $\mathrm{ml} / \mathrm{min}$ within $30 \mathrm{~min}$. The eluent was monitored by UV/VIS detector set at 242 $\mathrm{nm}$ and a Microsorb ${ }^{\mathrm{TM}} \mathrm{C} 18$ column $(5 \mu \mathrm{M}, 4.6 \mathrm{~mm} \times 25 \mathrm{~cm}$, Rainin instrument Co., Woburn, USA) was used.

\subsection{Histology}

The gerbils were sacrificed $72 \mathrm{~h}$ after ischemic insult. They were deeply anesthetized with ether and perfused transcardially with cold heparinized phosphatebuffered saline (PBS, pH 7.2) and 10\% formalin in PBS. The brains were removed from the skull and fixed in the same fixative for $24 \mathrm{~h}$. Thereafter the brains were embedded in paraffin and representative coronal sections $(6-\mu \mathrm{m}$ thick), which included the dorsal hippocampus, were obtained using a rotary microtome. Tissue sections were stained with hematoxylin and eosin. The hippocampal CA1 damage was determined by counting the surviving pyramidal neurons. The mean number of CA1 pyramidal neurons per millimeter for both hemispheres in a section of dorsal hippocampus was calculated for each group of the gerbils.

\subsection{Terminal Deoxynucleotidyl Transferase-Mediated dUTP Nick End-Labeling (TUNEL) Staining}

Histochemical staining for TUNEL was performed with a kit (Roche Diagnostic Co., USA). Tissue sections were deparaffinized in xylene and hydrated in a sequence of ethanol washes followed by a final wash in phosphate-buffered saline (PBS). Nuclei of tissue sections were stripped of proteins by incubation with proteinase $\mathrm{K}\left(20 \mu \mathrm{g} / \mathrm{ml}\right.$ in $10 \mathrm{mM}$ Tris $/ \mathrm{HCl}$, at $\left.37^{\circ} \mathrm{C}\right)$ for 15 minutes. The slices were then washed in distilled water and PBS and incubated in $0.3 \%$ hydrogen peroxide to remove endogenous peroxidases. After equilibration, each section was incubated with $50 \mu \mathrm{l}$ of TUNEL mixture ( $5 \mu \mathrm{l}$ of terminal deoxynucleotidyl transferase (TdT) and $45 \mu \mathrm{l}$ of fluorescence-labeled nucleotide) for $60 \mathrm{~min}$ at $37^{\circ} \mathrm{C}$. The sections were treated with horseradish peroxidase conjugated anti-fluorescence antibodies. After a detection of double strand breaks in genomic DNA with 2,3 '-diaminobenzidine tetrahydrochloride (DAB) $(0.5 \mathrm{mg} / \mathrm{ml}$ in 50 $\mathrm{mmol} / \mathrm{L}$ Tris-HCl buffer, $\mathrm{pH}$ 7.4) as a substrate for the peroxidase.

\subsection{Statistics}

Statistical analysis was performed using ANOVA followed by Scheffe's post-hoc test and significance refers to results where $\mathrm{p}<0.05$ was obtained.

\section{Results}

\subsection{Effect of Forebrain Ischemia on Polyamine Levels in the Hippocampus}

The changes in the hippocampal polyamine levels were examined $6 \mathrm{~h}, 12 \mathrm{~h}, 24 \mathrm{~h}$ or $72 \mathrm{~h}$ after ischemia. The PU level was significantly increased at $12 \mathrm{~h}, 24 \mathrm{~h}$, or $72 \mathrm{~h}$ after ischemia (respectively, $p<0.05$ ). The PU level was highest $12 \mathrm{~h}$ after 
ischemia compared with the sham-operated group (Figure 1(a)).

The hippocampal SD level also did not show significant changes compared with the sham-operated group (Figure 1(b)). The hippocampal SM levels were not also significantly changed after ischemia (Figure 1(c)).

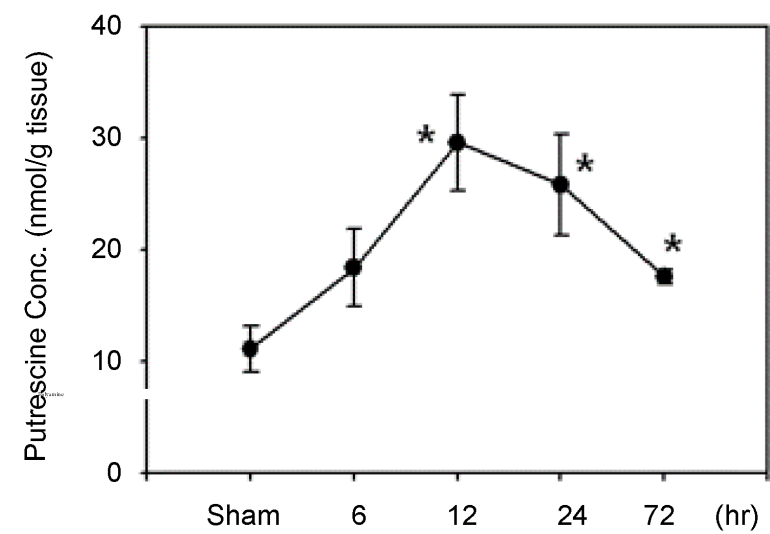

(a)

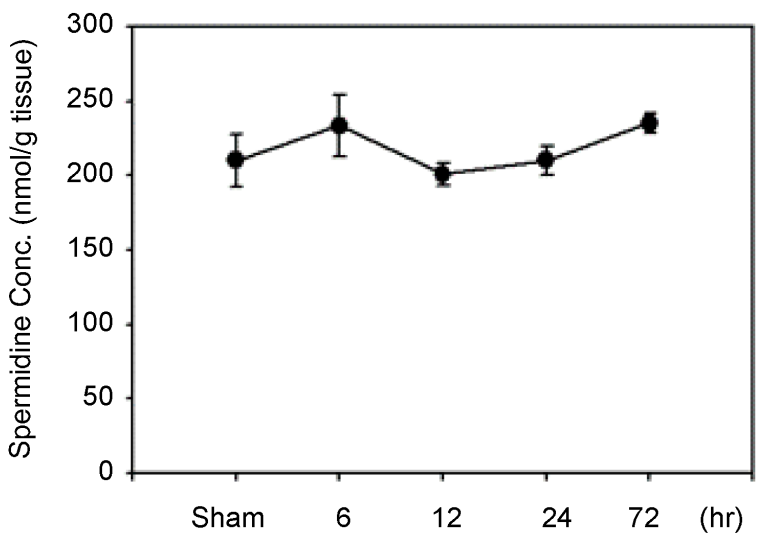

(b)

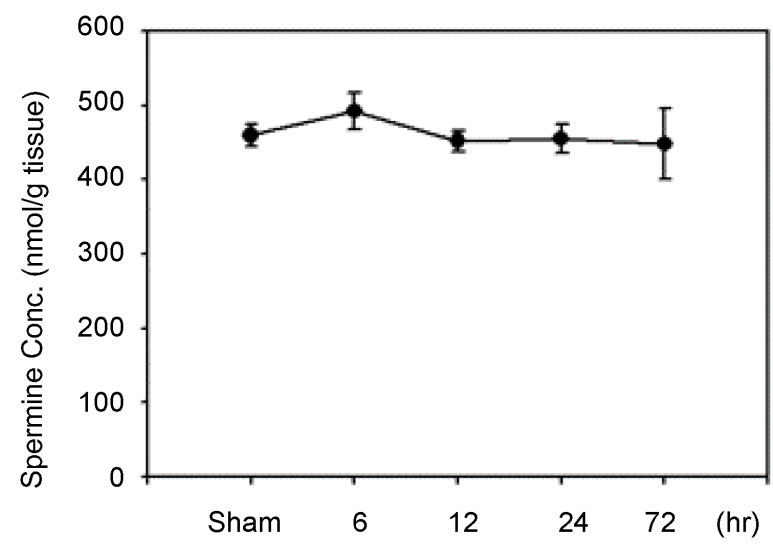

(c)

Figure 1. Polyamine (a) Putrescine; (b) Spermidine; and (c) Spermine) profiles of gerbil hippocampus in global ischemia $(6 \mathrm{~h}, 12 \mathrm{~h}, 24 \mathrm{~h}$, or $72 \mathrm{~h}$ after reperfusion). Polyamine levels are given in $\mathrm{nmol} / \mathrm{g}$ wet tissue. $\mathrm{N}=7$, respectively. Statistically significant differences compared to sham-operated group are indicated by ${ }^{*} \mathrm{p}<0.05,{ }^{* *} \mathrm{p}<0.01$. Conc: concentration. 


\subsection{Effect of Administration of L-Deprenyl in the Changes of Polyamine Levels}

Administration of L-deprenyl attenuated the increases of the hippocampal PU levels at $12 \mathrm{~h}$ after ischemia $(p<0.05$, Figure $2(\mathrm{a}))$. Administration of L-deprenyl did not change the SD or SM levels in the hippocampus following ischemia (Figure 2(b) and Figure 2(c)).

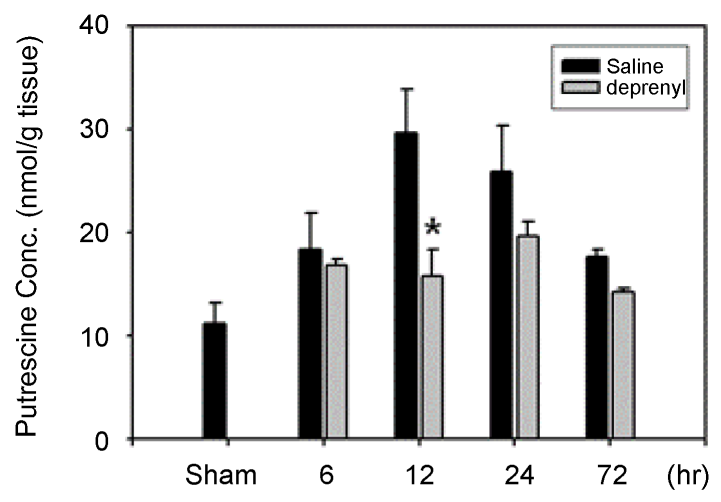

(a)

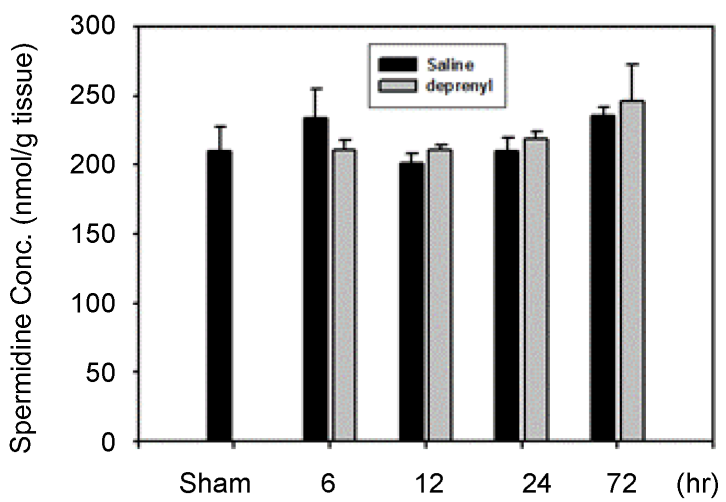

(b)

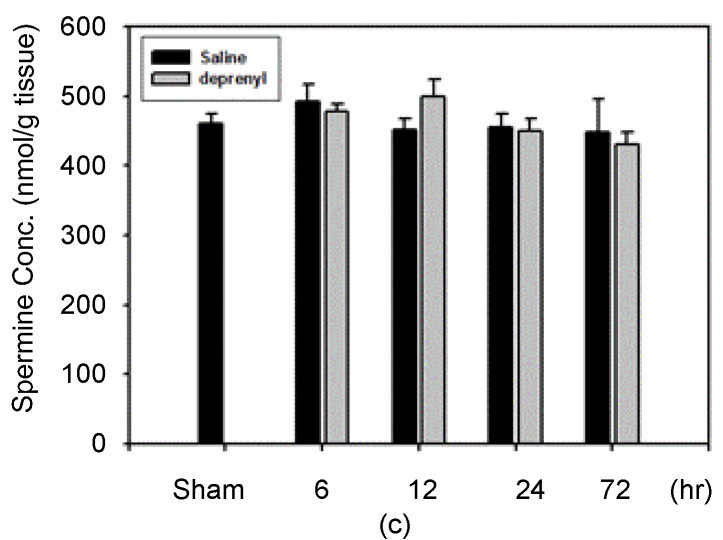

Figure 2. Changes of putrescine (a); spermidine (b) or spermine (c) levels in gerbil hippocampus after global ischemia and effect of L-deprenyl administration. Polyamine levels are given in $\mathrm{nmol} / \mathrm{g}$ wet tissue. $\mathrm{N}=7$, respectively. Statistically significant differences compared to saline-treated group are indicated by ${ }^{\star} \mathrm{p}<0.05$. Conc: concentration. 


\subsection{Histological Changes}

Histological examination of the nervous system demonstrated marked cell damage in the hippocampal CA1 region in the gerbils treated with a vehicle when compared with the sham-operated group (Figure 3(a) and Figure 3(b)). CA1 pyramidal neurons showed pyknosis, eosinophilia, karyorrhexia, and chromosome condensation in the vehicle-treated group (Figure 3(b)). This neuronal cell damage was inhibited by L-deprenyl administration. Administration of Ldeprenyl administered after ischemic insult significantly reduced neuronal damage $(p<0.05$, Figure $3(c)$ and Figure $3(d))$.

\subsection{TUNEL Staining}

In sham-operated group, there were no TUNEL staining positive cells in the hippocampal CA1 area (Figure 4(a)). Numerous cells in the hippocampal CA1 area were strongly positive for TUNEL staining after global ischemia and vehicle-treated group (Figure 4(b)). The number of normal viable cell in the global ischemia and L-deprenyl-treated group was more than that in the global ischemia and vehicle-treated group (Figure $4(\mathrm{c})$ ). For semi-quantification, Ldeprenyl adminstration significantly decrease the TUNEL staining-positive cells in compared with vehicle-treated group (Figure $4(\mathrm{~d}),{ }^{\star} \mathrm{P}<0.05$ ).
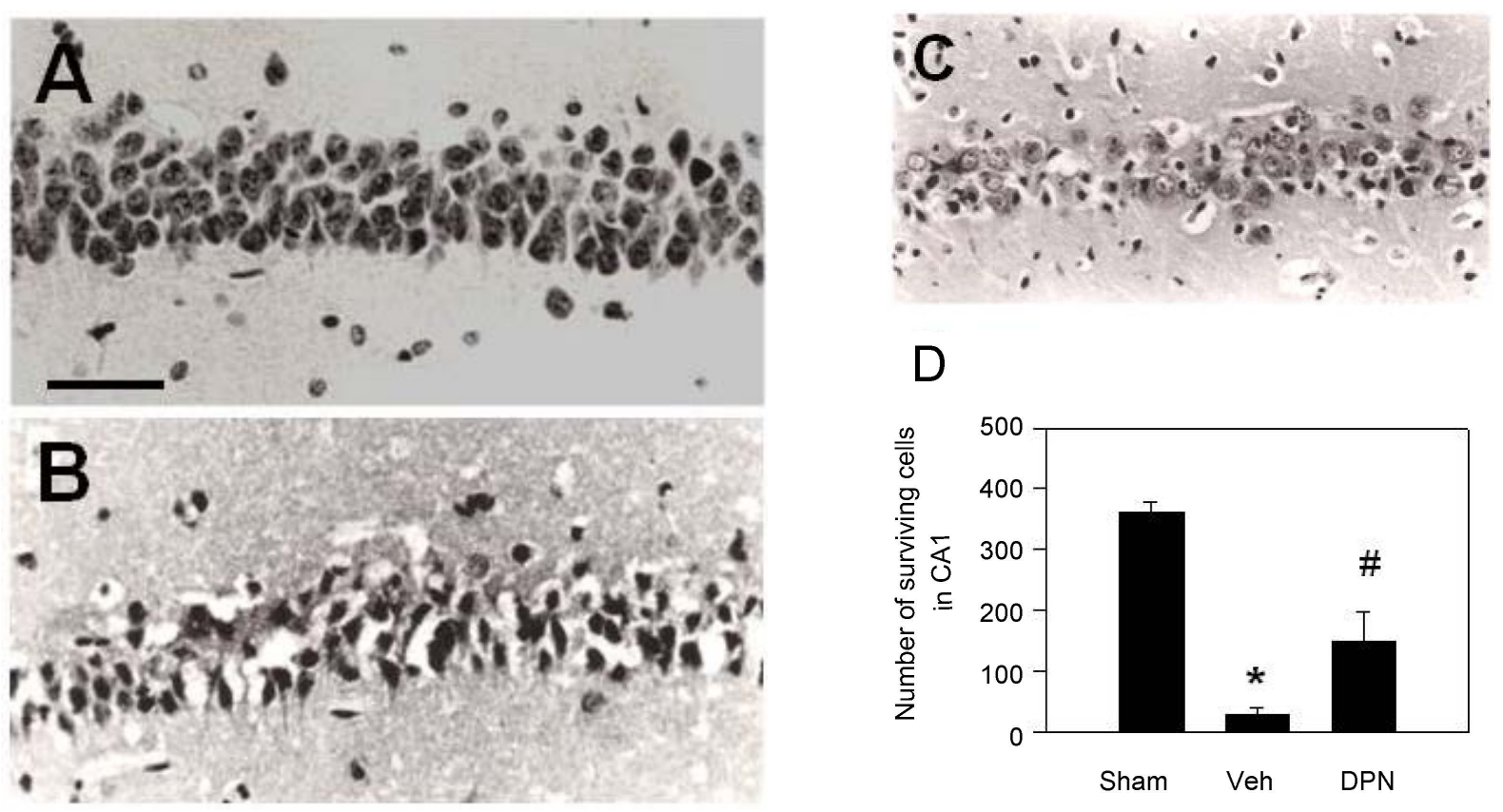

Figure 3. Protective effect of L-deprenyl on global ischemia-induced neuronal damage in hippocampal CA1 area of gerbil. Hippocampal CA1 pyramidal neurons in sham-operated group $(n=7)(a)$; Hippocampal CA1 pyramidal neurons in global ischemia and vehicle administration group $(\mathrm{n}=10)(\mathrm{b})$; Hippocampal CA1 pyramidal neurons in global ischemia and L-deprenyl administration $(n=10)(c)$; Remarkable reduction in the number of viable neurons at the 3 days after the ischemic episode when compared with sham-operated controls. Administration of L-deprenyl attenuated the ischemic neuronal injuries (d); After transient global ischemia, there are remarkable reduction of surviving neurons in gerbil hippocampus when compared with sham-operated controls $\left({ }^{\star} \mathrm{P}<0.05\right)$. Significant increase of surviving neurons in CA1 area is observed in DPN animals when compared with Veh $(\# \mathrm{P}<0.05)$. Data are presented as the mean \pm S.E.M. Sham: Sham-operated animals, Veh: vehicle-treated animals, DPN: L-deprenyl treated animals. Scale bar $=50 \mu \mathrm{m}$. 

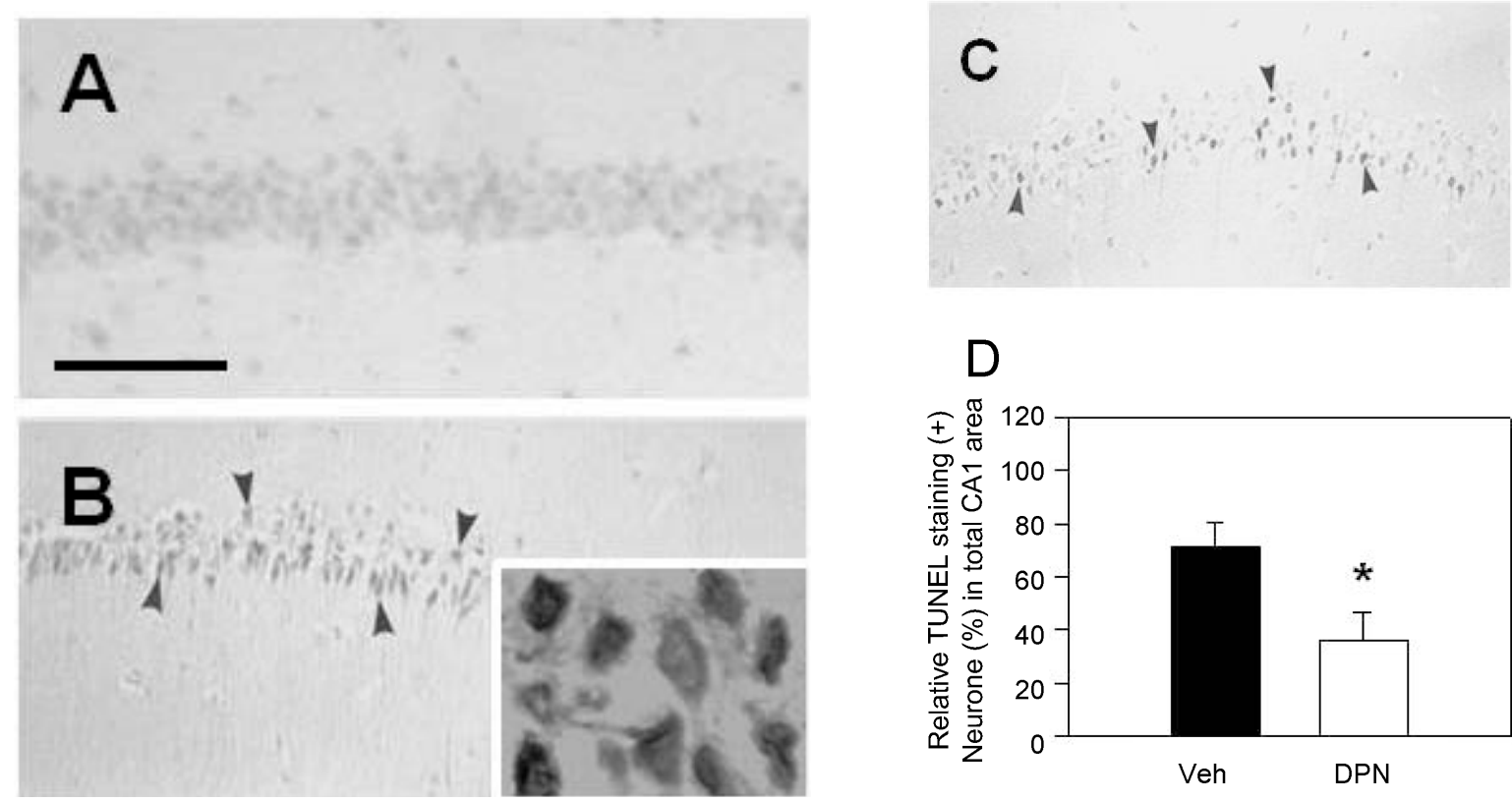

\section{D}

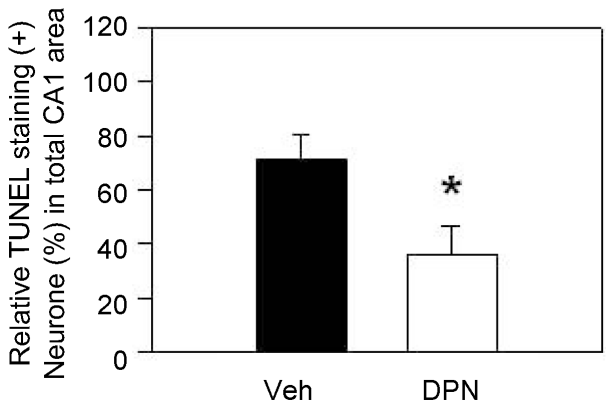

Figure 4. Effect of L-deprenyl on TUNEL staining in the hippocampal CA1 subsector 3 days after transient global ischemia in gerbil. Hippocampal CA1 pyramidal neurons in sham-operated group $(n=7)(a)$; Hippocampal CA1 pyramidal neurons in global ischemia and vehicle administration group $(\mathrm{n}=10)(\mathrm{b})$; Hippocampal CA1 pyramidal neurons in global ischemia and L-deprenyl administration $(\mathrm{n}=10)(\mathrm{c})$; Remarkable increase in the number of TUNEL staining (+)-cells at the 3 days after the ischemic episode when compared with sham-operated controls. Administration of L-deprenyl attenuated the TUNEL staining (+)-cells (D). Significant decrease of TUENL staining $(+)$-cells in CA1 area is observed in L-deprenyl-treated animals when compared with vehicle-treated animals $\left({ }^{*} \mathrm{P}<0.05\right)$. Data are presented as the mean \pm S.E.M. Veh: vehicle-treated animals, DPN: L-deprenyl-treated animals. Scale bar $=50 \mu \mathrm{m}$.

\section{Discussion}

L-Deprenyl, also named selegiline, is selective and irreversible inhibitor of monoamine oxidase B (MAO-B) widely used in the management of Parkinson's disease (PD). L-Deprenyl is known to have neuroprotective properties, including antioxidant, anticonvulsant actions.

Degeneration of nigrostriatal dopaminergic neurons is the major pathogenic substrate of PD. Inhibitors of monoamine oxidase B (MAO-B) have been used in the treatment of $\mathrm{PD}$ and at least one of them, i.e., L-deprenyl, also displays antioxidant activity. Dopamine (DA) autoxidation produces reactive oxygen species implicated in the loss of dopaminergic neurons in the nigrostriatal pathway. But there is little report that L-deprenyl has neuroprotective effect against delayed neuronal injury in global ischemia.

These results show L-deprenyl is effective as a prophylactic treatment for neuronal injury when it is administered before ischemia but a further study need to know the effects of administration of L-deprenyl after ischemia and at given times after reperfusion.

\subsection{Effects of Administration of L-Deprenyl on the Changes of Polyamine Level in Gerbil Brain Regions after Transient Global Ischemia}

It is suggested that polyamines released from necrotic neurons into the extracel- 
lular compartment bind to the NMDA receptor of cells located in close vicinity and thus render neurons vulnerable to subtoxic levels of excitotoxins. Several researchers examined the changes in brain polyamine levels after focal or global ischemia [6] [11] [13]. Various kinds of stimuli or stresses such as seizures, excitotoxicity, and traumatic brain injury modify the ornithine decarboxylase (ODC), the regulatory enzyme in the polyamine biosynthesis [4] [5] [10] [27]. These changes may be related to modifications of intracellular calcium ion fluxes because polyamines increase the cytosolic amino acids. Some authors have shown discrepancies between ODC activity and the concentration of polyamine [28], a finding suggesting that the latter might be more useful than the former.

In this study, PU levels in cortex and hippocampus increased after transient global ischemia. These changes in PU levels bear a strong similarity to those described by Paschen et al. [13]. The diamine precursor of polyamines, PU is normally in low level and long lasting accumulation of PU may be harmful [13]. An association between brain damage and high PU levels in the ischemic brain has also been found previously suggesting a role for PU in mediating the ischemic damage. ODC and polyamines are thought to be important in the generation of edema and neuronal cell loss associated with cerebral ischemia [13]. Baskaya et al. [5] suggested that polyamines may play a role in posttraumatic brain edema formation particularly in brain regions.

Polyamines are known to increase cytosolic calcium ion concentration [29] [30] and induce the release of excitatory amino acid [27]. A remarkable increase of the extracellular concentration of excitatory amino acids including glutamate, induced by cerebral ischemia leading to a large amount of calcium ion influx through glutamate receptor in neurons and neuronal injury [31]. PU levels particularly correlate with the density of cell necrosis [13]. PU might be a reliable marker for acute pathology in brain tissue injury [32]. Tissue PU increased in the penumbra region that developed brain edema in permanent focal cerebral ischemia [6]. In addition, the blockade of ODC resulted in a protective effect against focal or global ischemic brain damage [15] and partially antagonized the convulsant activity [33] suggesting that polyamine metabolism plays a role in the development of neuronal injuries following brain ischemia or epileptic seizure. In regarding the effect of L-deprenyl on the PU level, although there is no definite evidences, we can suggest two possibilities. First, L-deprenyl attenuates the harmful accumulation of PU by influence on the polyamine metabolism. Second, L-deprenyl-induced neuroprotection due to antioxidant effect or anti-apoptotic effect may decrease the PU response to excitotoxicity.

In this study, SD and SM levels in the cortex and hippocampus showed no significant changes after ischemia. These are in agreement with results of de Vera et al. [33] and Paschen et al. [12]. In addition, L-deprenyl did not show any influences on the SD and SM levels. Activation of interconversion pathway enzymes, SD/SM N ${ }^{1}$-acetyltranseferase [34] and PA oxidase [35] which convert SM to $\mathrm{SD}$ and $\mathrm{SD}$ to $\mathrm{PU}$, is a probable major factor in PU accumulation [36]. In addition, SD has been shown to bind to NMDA-gated calcium ionophores in- 
creasing also the affinity of $\left[{ }^{3} \mathrm{H}\right]-\mathrm{MK}-801$ for NMDA receptor [3] [37]. Therefore, the reduction of SD level may be a compensatory mechanism unrelated to the ODC activation against ischemic insult. Tissue PU levels change to a remarkable degree than those of SD and SM after various pathological conditions [4] [5] [6] [9] [12] [14] [30].

The results of this study suggest that administration of L-deprenyl early after ischemia is effective to attenuate the increase of PU levels because polyamine biosynthesis increased rapidly after ischemia. However, the role of polyamines, especially $\mathrm{PU}$, in the pathogenesis of brain ischemia is not clear and needs to be further studied.

\subsection{Effect of Administration of L-Deprenyl against Neuronal Damage after Transient Global Ischemia}

The present study shows the neuroprotective effect of administration of L-deprenyl against ischemic neuronal damage. Many researchers have described the effects of L-deprenyl in inhibition of free radical-induced lipid peroxidation and apoptosis in neural tissue. Recently, the antioxidant effects of L-deprenyl were extensively studied. L-Deprenyl protects lipid peroxidation [22] and increases the scavenging effect of anti-oxidant enzymes [38]. Wu et al. [39] reported Ldeprenyl-induced facilitation of nigral neuron recovery by its anti-oxidant effect. In addition, L-deprenyl has been shown to protect the neuronal injury and function after exposure to beta-amyloid protein [40].

In transient global ischemia, neuronal damage shows mainly apoptotic pathway in hippocampal pyramidal cell layer [41] [42]. In previous studies, L-deprenyl shows anti-apoptotic effect in various neuronal damage models [43]. In this study animals that received L-deprenyl treatment displayed a significant decrease in the number of TUNEL staining positive neurons in the hippocampal CA1 region.

It has been well known that oxygen radical-induced lipid peroxidation has been strongly suggested to play a role in ischemic neuronal damage [44] [45]. Recently, a variety of studies have examined the neuroprotective properties of antioxidants in brain ischemia [46] [47]. These results demonstrated that administration of L-deprenyl has neuroprotective effect against transient global ischemia-induced neuronal injury in gerbils. L-Deprenyl attenuated the increase of putrescine level in the cerebral cortex and hippocampus and the neuronal damages in the hippocampal CA1 region after ischemia. Administration of Ldeprenyl did not show complete neuroprotection, it seems to be a promising strategy for attenuation of global ischemia-induced neuronal injury.

The present data show that the administration of L-deprenyl attenuates the ischemia-induced increases in PU levels and has a neuroprotective effect against hippocampal neuronal damage in a gerbil model of global ischemia. L-Deprenyl is neuroprotective against neuronal damage after transient global ischemia. These findings suggest that L-deprenyl may have a promise in the acute treatment of stroke. 


\section{Acknowledgements}

This work was supported by the research promoting grant from the Keimyung University Dongsan Medical Center in 2012 and the National Research Foundation of Korea (NRF) Grant funded by the Korean Government (MSIP) (No. 2014R1A5A2010008).

\section{References}

[1] Pegg, A.E. (1986) Recent Advances in the Biochemistry of Polyamines in Eukaryotes. Biochemical Journal, 234, 249-262. https://doi.org/10.1042/bj2340249

[2] Tabor, C.W. and Tabor, H. (1984) Polyamines. Annual Review of Biochemistry, 53, 749-790. https://doi.org/10.1146/annurev.bi.53.070184.003533

[3] Williams, K., Romano, C. and Molinoff, P.B. (1989) Effects of Polyamines on the Binding of [3H]-MK-801 to the NMDA Receptor: Pharmacological Evidence for the Existence of a Polyamine Recognition Site. Molecular Pharmacology, 36, 575-581.

[4] Baskaya, M.K., Rao, A.M., Prasad, M.R. and Dempsey, R.J. (1996) Regional Activity of Ornithine Decarboxylase and Edema Formation after Traumatic Brain Injury. Neurosurgery, 38, 140-145. https://doi.org/10.1097/00006123-199601000-00033

[5] Baskaya, M.K., Rao, A.M., Puckett, L., Prasad, M.R. and Dempsey, R.J. (1996) Effect of Difluoro-Methylornithine Treatment on Regional Ornithine Decarboxylase Activity and Edema Formation after Experimental Brain Injury. Journal of Neurotrauma, 13, 85-92. https://doi.org/10.1089/neu.1996.13.85

[6] Baskaya, M.K., Rao, A.M., Dogan, A., Donaldson, D., Gellin, G. and Dempsey, R.J. (1997) Regional Brain Polyamine Levels in Permanent Focal Cerebral Ischemia. Brain Research, 744, 302-308.

[7] Gilad, G.M. and Gilad, V.H. (1992) The Brain Polyamine-Stress-Response: Recurrence after Repetitive Stressor and Inhibition by Lithium. Journal of Neurochemistry, 67, 1992-1996. https://doi.org/10.1046/j.1471-4159.1996.67051992.x

[8] Gilad, G.M. and Gilad, V.H. (1992) Polyamines in Neurotrauma Ubiquitous Molecules in Search of a Function. Biochemical Pharmacology, 44, 401-407.

[9] Lee, Y.K., Lee, S.R. and Kim, C.Y. (2000) Melatonin Attenuates the Changes in Polyamine Levels Induced by Systemic Kainate Administration in Rat Brains. Journal of Neurological Science, 178, 124-131.

[10] Martinez, E., de Vera, N. and Artigas, F. (1991) Differential Response of Rat Brain Polyamines to Convulsant Agents. Life Science, 48, 77-84.

[11] Dogan, A., Rao, A.M., Hatcher, J., Rao, V.A.R., Baskaya, M.K. and Dempsey, R.J. (1999) Effects of MDL 72527, a Specific Inhibitor of Polyamine Oxidase, on Brain Edema, Ischemic Injury Volume, and Tissue Polyamine Levels in Rats after Temporary Middle Cerebral Artery Occlusion. Journal of Neurochemistry, 72, 765-770. https://doi.org/10.1046/j.1471-4159.1999.0720765.x

[12] Paschen, W., Hallmayer, J. and Mies, G. (1987) Regional Profile of Polyamines in Reversible Cerebral Ischemia of Mongolian Gerbils. Neurochemical Pathololgy, 7, 143-156. https://doi.org/10.1007/BF02834214

[13] Paschen, W., Schmidt-Kastner, R., Hallmayer, J. and Djuricic, B. (1988) Polyamines in Cerebral Ischemia. Neurochemical Pathololgy, 9, 1-20.

[14] Dempsey, R.J., Carney, J.M. and Kindy, M.S. (1991) Modulation of Ornithine Decarboxylase mRNA Following Transient Ischemia in the Gerbil Brain. Journal of Cerebral Blood Flow and Metabolism, 11, 979-985. https://doi.org/10.1038/jcbfm.1991.164 
[15] Kindy, M.S., Hu, Y. and Dempsey, R.J. (1994) Blockade of Ornithine Decarboxylase Enzyme Protects against Ischemic Brain Damage. Journal of Cerebral Blood Flow and Metabolism, 14, 1040-1045. https://doi.org/10.1038/jcbfm.1994.136

[16] Philips, S.R. and Boulton, A.A. (1979) The Effect of Monoamine Oxidase on Some Srylalbylamines in Rat Striatum. Journal of Neurochemistry, 33, 159-167. https://doi.org/10.1111/j.1471-4159.1979.tb11718.x

[17] Knoll, J. (1993) The Pharmacological Basis of the Beneficial Effects of (-) Deprenyl (Selegiline) in Parkinson's and Alzheimer's Disease. Journal of Neural Transmission. Supplementum, 40, 69-91.

[18] Tetrude, J.W. and Langstone, J.W. (1989) The Effect of Deprenyl (Selegiline) on the Natural History of Parkinson's Disease. Science, 245, 519-522.

https://doi.org/10.1126/science.2502843

[19] Knoll, J. (1978) The Possible Mechanisms of Action of (-) Deprenyl in Parkinson's Disease. Journal of Neural Transmission, 43, 177-198. https://doi.org/10.1007/BF01246955

[20] Kabins, D. and Gershon, S. (1990) Potential Applications for Monoamine Oxidase B Inhibitors. Dementia, 1, 323-348.

[21] Carrillo, M.C., Kitani, K., Kanai, S., Sato, Y. and Ivy, G.O. (1992) The Ability of (-) Deprenyl to Increase Superoxide Dismutase Activities in the Rat Is Tissue and Brain Region Selective. Life Science, 50, 1985-1992.

[22] Maia, F.D., Pitombeira, B.S., Araujo, D.T., Cunha, G.M. and Viana, G.S. (2004) L-Deprenyl Prevents Lipid Peroxidation and Memory Deficits Produced by Cerebral Ischemia in Rats. Cellular and Molecular Neurobiology, 24, 87-100. https://doi.org/10.1023/B:CEMN.0000012727.59502.c5

[23] Cooper, J. (1991) Drug Treatment of Alzheimer's Disease. Archives of Internal Medicine, 151, 245-249. https://doi.org/10.1001/archinte.1991.00400020021006

[24] Davis, K.L. and Haroutunian, V. (1993) Strategies for the Treatment of Alzheimer's Disease. Neurology, 43, 52-55.

[25] Loscher, W. and Lehmann, H. (1996) L-Deprenyl (Selegiline) Exerts Anticonvulsant Effects against Different Seizure Types in Mice. The Journal of Pharmacology and Experimental Therapeutics, 277, 1410-1417.

[26] Matsushita, K., Kitagawa, K., Matsuyama, T., Ohtsuki, T., Taguchi, A., Mandai, K., Mabuchi, T., Yagita, Y., Yanagihara, T. and Matsumoto, M. (1996) Effect of Systemiczinc Administration on Delayed Neuronal Death in the Gerbil Hippocampus. Brain Research, 743, 362-365.

[27] Bondy, S.C. and Walker, C.H. (1986) Polyamine Contribute to Calcium-Stimulated Release of Aspartate from Brain Particulate Fractions. Brain Research, 371, 96-100.

[28] Trout, J.J., Koenig, H., Goldstone, A.D. and Lu, C.Y. (1986) Blood Brain Barrier Breakdown by Cold Injury. Polyamine Signals Mediate Acute Stimulation of Endocytosis, Vesicular Transport, and Microvillus Formation in Rat Cerebral Capillaries. Laboratory Investigation, 55, 622-631.

[29] Iqbal, Z. and Koenig, H. (1985) Polyamines Appear to Be Second Messengers in Mediating $\mathrm{Ca}^{++}$Fluxes and Neurotransmitter Release Potassium-Depolarized Synaptosomes. Biochemical and Biophysical Research Communications, 133, 563-573. https://doi.org/10.1038/305530a0

[30] Koenig, H., Goldsteine, A.D. and Lu, Ch.-Y. (1983) Polyamines Regulate Calcium Fluxes in a Rapid Plasma Membrane Response. Nature, 305, 530-534. https://doi.org/10.1146/annurev.ne.13.030190.001131

[31] Choi, D.W. and Rothman, S.M. (1990) The Role of Glutamate Neurotoxicity in 
Hypoxia-Ischemic Neuronal Death. Annual Review of Neuroscience, 13, 171-182.

[32] Najm, I., el-Skaf, G., Massicotte, G., Vanderklish, P., Lynch, G. and Baudry, M. (1992) Changes in Polyamine Levels and Spectrin Degradation Following KainateInduced Seizure Activity: Effect of Difluoromethylornithine. Experimental Neurology, 116, 345-354. https://doi.org/10.1111/j.1471-4159.1991.tb02091.x

[33] De Vera, N., Artigas, F., Serratosa, J. and Martinez, E. (1991) Changes in Polyamine Levels in Rat Brain after Systemic Kainic Acid Administration: Relationship to Convulsant Activity and Brain Damage. Journal of Neurochemistry, 57, 1-8.

[34] Zoli, M., Pedrazzi, P., Zini, I. and Agnati, L.F. (1996) Spermidine/Spermine $N 1$-Acetyltransferase mRNA Levels Show Marked and Region-Specific Changes in the Early Phase after Transient Forebrain Ischemia. Molecular Brain Research, 38, 122-134.

[35] Baudry, M. and Najm, I. (1997) Kainate-Induced Seizure Activity Stimulates the Polyamine Interconversion Pathway in Rat Brain. Neuroscience Letters, 171, 151154.

[36] Rao, A.M., Hatcher, J.F., Baskaya, M.K. and Dempsey, R.J. (1998) Simultaneous Assay of Ornithine Decarboxylase and Polyamines after Central Nervous System Injury in Gerbil and Rat. Neuroscience Letters, 256, 65-68. https://doi.org/10.1111/j.1471-4159.1988.tb01818.x

[37] Ransom, R.W. and Stec, N.L. (1988) Cooperative Modulation of [3H] MK-801 Binding to the NMDA Receptor-Ion Channel Complex by l-Glutamate, Glycine, and Polyamines. Journal of Neurochemistry, 51, 830-836.

https://doi.org/10.1007/s12192-010-0177-y

[38] Subramanian, M.V. and James, T.J. (2010) Age-Related Protective Effect of Deprenyl on Changes in the Levels of Diagnostic Marker Enzymes and Antioxidant Defense Enzymes Activities in Cerebellar Tissue in Wistar Rats. Cell Stress Chaperones, 15, 743-751. https://doi.org/10.1111/j.1749-6632.1996.tb39078.x

[39] Wu, R.M., Murphy, D.L. and Chiueh, C.C. (1996) Suppression of Hydroxyl Radical Formation and Protection of Nigral Neurons by l-Deprenyl (Selegiline). Annals of the New York Academy of Sciences, 15, 379-390.

[40] Tsunekawa, H., Noda, Y., Mouri, A., Yoneda, F. and Nabeshima, T. (2008) Synergistic Effects of Selegiline and Donepezil on Cognitive Impairment Induced by Amyloid Beta (25-35). Behavioral Brain Research, 190, 224-232. https://doi.org/10.1074/jbc.M505843200

[41] Hetz, C., Vitte, P.A., Bombrun, A., Rostovtseva, T.K., Montessuit, S., Hiver, A., Schwarz, M.K., Church, D.J., Korsmeyer, S.J., Martinou, J.C. and Antonsson, B. (2005) Bax Channel Inhibitors Prevent Mitochondrion-Mediated Apoptosis and Protect Neurons in a Model of Global Brain Ischemia. Journal of Biological Chemistry, 280, 42960-42970. https://doi.org/10.1007/BF00294608

[42] Yamamoto, K., Hayakawa, T., Mogami, H., Akai, F. and Yanagihara, T. (1990) Ultrastructural Investigation of the CA1 Region of the Hippocampus after Transientcerebral Ischemia in Gerbil. Acta Neuropathologica, 80, 487-492.

[43] Whaley, J.G., Tharakan, B., Smith, B., Hunter, F.A. and Childs, E.W. (2009) (-)-Deprenyl Inhibits Thermal Injury-Induced Apoptotic Signaling and Hyperpermeability in Microvascular Endothelial Cells. Journal of Burn Care \& Research, 30, 1018-1027.

[44] Chan, P.H., Kawase, M., Murakami, K., Chen, S.F., Li, Y., Calagui, B., Reola, L., Carlson, E. and Epstein, C.J. (1998) Overexpression of SOD1 in Transgenic Rats Protects Vulnerable Neurons against Ischemic Damage after Global Cerebral Ischemia and Reperfusion. Journal of Neuroscience, 18, 8292-8299. 
https://doi.org/10.1161/01.STR.30.9.1962

[45] Kawase, M., Murakami, K., Fujimura, M., Morita-Fujimura, Y., Gasche, Y., Kondo, T., Scott, R.W. and Chan, P.H. (1999) Exacerbation of Delayed Cell Injury after Transient Global Ischemia in Mutant Mice with CuZn Superoxide Dismutase Deficiency. Stroke, 30, 1962-1968.

[46] Block, F., Schmitt, W. and Schwarz, M. (1995) The Antioxidant LY 231617 Ameliorates Functional and Morphological Sequelae Induced by Global Ischemia in Rats. Brain Research, 694, 308-311.

[47] O’Neill, M.J., Hicks. C., Ward. M. and Panetta, .JA. (1997) Neuroprotective Effects of the Antioxidant LY231617 and NO Synthase Inhibitors in Global Cerebral Ischemia. Brain Research, 760, 170-178.

Submit or recommend next manuscript to SCIRP and we will provide best service for you:

Accepting pre-submission inquiries through Email, Facebook, LinkedIn, Twitter, etc. A wide selection of journals (inclusive of 9 subjects, more than 200 journals)

Providing 24-hour high-quality service

User-friendly online submission system

Fair and swift peer-review system

Efficient typesetting and proofreading procedure

Display of the result of downloads and visits, as well as the number of cited articles Maximum dissemination of your research work

Submit your manuscript at: http://papersubmission.scirp.org/

Or contact ijoc@scirp.org 